\title{
As espécies de tauari (Lecythidaceae) em florestas de terra firme da Amazônia: padrões de distribuição geográfica, abundâncias e implicações para a conservação
}

\author{
Lilian Costa Procópio ${ }^{1,5}$, Marc Gayot ${ }^{2}$, Plínio Sist ${ }^{3}$ e Isolde D. K. Ferraz ${ }^{4}$
}

Recebido em 30/12/2009. Aceito em 28/05/2010

\begin{abstract}
RESUMO - (As espécies de tauari (Lecythidaceae) em florestas de terra firme da Amazônia: padrões de distribuição geográfica, abundâncias e implicações para a conservação). Conhecer a distribuição de uma espécie é essencial para o conhecimento de sua ecologia e conservação. Neste estudo, foram levantadas a composição, a abundância, a estrutura diamétrica e a distribuição geográfica das espécies de tauari (Lecythidaceae), um dos grupos de árvores mais explorados na Amazônia. Foram utilizados dados de herbários para definir a área de distribuição das espécies e inventários em seis áreas do bioma (totalizando 401,25 ha) para estimar abundâncias e estruturas diamétricas. Das 14 espécies ocorrentes na Amazônia, nove foram encontradas nos inventários. Couratari guianensis apresentou a maior área de distribuição contínua, porém sempre com densidades baixas. Couratari stellata apresentou a segunda maior área de distribuição, porém disjunta e, em geral, com densidades altas. Cariniana micrantha e Couratari multiflora apresentaram ampla distribuição e densidades variáveis, enquanto a maioria das demais espécies mostrou distribuição regional ou endêmica, e densidades menores que um indivíduo por hectare. A classificação das espécies em relação ao tipo de raridade divergiu daquelas descritas para Couratari guianensis e C. multiflora. Os resultados ressaltam a escassez de dados sobre espécies madeireiras nas regiões mais desmatadas da Amazônia, a necessidade do levantamento da abundância populacional local e regional para a melhor caracterização do seu padrão de distribuição e fornecem bases para a revisão das categorias e critérios de ameaças das espécies de Couratari na lista vermelha da IUCN.
\end{abstract}

Palavras-chave: Couratari, espécies madeireiras, espécies raras, estrutura diamétrica, manejo florestal

\begin{abstract}
Tauari” species (Lecythidaceae) in non-flooded Amazon forest: patterns of geographic distribution, abundance, and implications for conservation). Understanding the range of a species is essential to understanding its ecology and conservation. In this study we collected data on the composition, abundance, diametric structure, and geographic distribution of "tauari" species (Lecythidaceae), which are among the most exploited timber trees of the Amazonian forest. We used herbarium data to define the areas of distribution and inventories of 401.25 ha from six areas of Amazonia to list species for estimating abundance and diametric structure. Of the 14 species that occur in the biome, nine were sampled in the inventories. Couratari guianensis had the largest continuous area of distribution, but always at low densities. Couratari stellata had the second largest distribution, but it was discontinuous and usually at high densities. Cariniana micrantha and Couratari multiflora had wide distributions and variable densities, whereas most of the other species showed regional or restricted ranges and densities below one individual per hectare. The classification of species according to rarity type diverged from that described for Couratari guianensis and C. multiflora. These results point out the lack of data for timber species in the most deforested regions of Amazonia, the need for local and regional abundance investigation for better understanding of distribution patterns, and to provide support for reviewing the categories and criteria of threats of Couratari species on the IUCN Red List.
\end{abstract}

Key words: Couratari, diametric structure, rare species, forest management, timber species

\section{Introdução}

No Brasil, tauari corresponde às espécies de três gêneros de Lecythidaceae: Allantoma, Cariniana e Couratari, que são agrupadas no comércio madeireiro devido às suas características dendrológicas (Procópio \& Secco 2008). Este estudo está focado nas espécies das florestas de terra firme da Amazônia popularmente conhecidas como tauari, nome oficial dessas espécies quando vendidas no mercado internacional (ITTO 2005), mas que também são conhecidas por nomes locais correspondentes, como maho-cigare na Guiana Francesa (Gourlet-Fleury et al. 2004), ingie-pipa no Suriname e wadara na Guiana (Marín \& Flores 2003). Em 2000, no Estado do Amazonas, a madeira de tauari foi a décima quarta mais utilizada na indústria de laminado (Lima et al. 2005); em 2006, já aparecia entre as 10 mais comercializadas no mercado de madeira serrada e madeira em tora (IBAMA 2006).

No geral, as espécies de tauari incluem árvores de grande porte; Couratari stellata e Cariniana micrantha são consideradas as árvores mais altas dentre as Lecythidaceae, alcançando até $60 \mathrm{~m}$ de altura (Mori \& Swarthout 2007) e se destacando entre as emergentes em algumas regiões da Amazônia (Mori \& Boom 1987; Hopkins 2005). No campo, elas são reconhecidas pelas folhas simples e alternas, casca fibrosa e fissurada (exceto Couratari multiflora, espécie de porte médio, com casca escamosa) e pela forma da base do tronco, que também distingue os gêneros: em Couratari, a base apresenta raízes tabulares altas e estreitas; em Cariniana, a base é cilíndrica ou dilatada; e, em Allantoma, é frequentemente cilíndrica (Huang et al. 2008; Procópio \& Secco 2008). A casca, se cortada, é vermelha a rosada em Cariniana e branca a amarelada em Allantoma e Couratari (Procópio \& Secco 2008). Todos os gêneros apresentam frutos tipo pixídio, deiscentes, cilíndricos ou campanulados, que permanecem na copa por muito tempo após a dispersão das sementes (Prance \& Mori 1979; Mori \& Prance 1990; Mori \& Lepsch-Cunha 1995; Procópio \& Secco 2008). A

\footnotetext{
Instituto Nacional de Pesquisas da Amazônia, Coordenação de Pesquisas em Ecologia, Manaus, AM, Brasil

2 Office National des Fôrets (ONF), Reserva de Montabo, Caiena, Guiana Francesa

3 Centre de Coopération Internationale en Recherche Agronomique pour le Développement (CIRAD), Embrapa Recursos Genéticos e Biotecnológicos, Brasília, DF, Brasil

4 Instituto Nacional de Pesquisas da Amazônia, Coordenação de Pesquisas em Silvicultura Tropical (INPA-CPST), Manaus, AM, Brasil

5 Autora para correspondência: 1cprocopio@yahoo.com.br
} 
casca fibrosa e o tipo de fruto possibilitam o reconhecimento do tauari até mesmo por identificadores com pouca experiência. No entanto, as características do tronco e das folhas, quando analisadas em conjunto, permirtem a diferenciação das espécies (Procópio \& Secco 2008).

O agrupamento de espécies por mateiros, juntamente com a desatualização da nomenclatura botânica nas listas de inventários, pode ter consequências ecológicas e comerciais importantes (Martins-da-Silva et al. 2003; Gayot \& Sist 2004; Procópio \& Secco 2008). Por exemplo, Couratari pulchra Sandwith, sinônimo de Couratari guianensis (Mori \& Prance 1990), vinha sendo citada nos relatórios oficiais de controle de comercialização da madeira até 2008 (IBAMA 2007; IDEFLOR 2008). Huang et al. (2008) transferiram Cariniana decandra Ducke, C. integrifolia Ducke e $C$. pauciramosa W.A. Rodrigues para o gênero Allantoma; a primeira foi citada como tauari por Procópio \& Secco (2008) e as outras duas são citadas na lista vermelha da IUCN (2010) como vulneráveis e em perigo de extinção, respectivamente, sem atualização da nomenclatura.

$\mathrm{Na}$ Amazônia, os inventários de espécies arbóreas destacam Lecythidaceae, juntamente com Burseraceae e Sapotaceae, como predominantes em riqueza e abundância (Oliveira 1997; Oliveira \& Amaral 2004; Hopkins 2005; Luizão \& Vasconcelos 2005; Azevedo 2006; ter Steege et al. 2006). Contudo, dados de inventários florestais na Amazônia central e oriental (Prance \& Mori 1979; Mori \& Lepsch-Cunha 1995; Procópio \& Secco 2008) mostraram que pode haver diferenças locais importantes em relação à distribuição espacial, à dispersão e à abundância das espécies de Lecythidaceae. Considerando as dimensões da Amazônia e a heterogeneidade geomorfológica e climática que contribuem para os padrões de distribuição geográfica das espécies, os estudos populacionais para fins de conservação devem ter dimensão continental (Oliveira 1997; ter Steege 1998).

Muitas propostas de subdivisão fitogeográfica da Amazônia (Daly \& Prance 1989) e de definição de áreas de conservação (ter Steege 1998) estão baseadas em informações sobre a distribuição geográfica das espécies e os endemismos. Assim como a distribuição, a abundância das populações soma critérios determinantes para sua caracterização ecológica (Bawa \& Ashton 1991) e também funciona como indicador de vulnerabilidade de espécies arbóreas de interesse madeireiro (Martini et al 1998). Todavia, ainda são poucos os trabalhos que avaliam esses parâmetros em grande amplitude geográfica (Oliveira 1997; Ruokolainen et al. 2002).

Registros de herbários são fontes confiáveis para mapear a distribuição das espécies. Contudo, a definição de áreas de distribuição com base em dados de coletas apresenta riscos; o principal deles é que esses mapas estejam refletindo basicamente o esforço amostral em vez da real distribuição das espécies (Mori \& Prance 1990; Schulman et al. 2007). A consequência mais evidente deste artefato amostral pode ser uma riqueza subestimada em regiões pouco coletadas. No nível de espécie, outro problema é a pequena amostragem em relação à ocorrência de espécies de baixa abundância local ou geral, o que pode levar à definição de populações reduzidas ou falsamente fragmentadas. Assim, ao aproximar áreas e padrões de distribuição das espécies com base em amostras de herbário é necessário ter em mente essas limitações do método.

Considerando que coletas botânicas são geralmente realizadas de maneira casual, é possível admitir que o esforço de coleta em escala amazônica, embora geograficamente desigual (Hopkins 2007), é feito independentemente das espécies de tauari e, assim, possam embasar uma primeira comparação das áreas de distribuição dessas espécies. Além disso, os inventários de caracterização e monitoramento da estrutura das populações são fundamentais para suprir lacunas nos campos da silvicultura, manejo e conservação das espécies (Leite 2007).

Tendo em vista a relevância das espécies de tauari na flora da Amazônia e no mercado madeireiro, este trabalho pretende caracterizar a composição, a abundância e a ocorrência geográfica de suas espécies em diferentes regiões do bioma para definir o padrão de distribuição das espécies e propor medidas para a conservação no âmbito do manejo florestal e do desmatamento. Nesse contexto, as seguintes perguntas foram abordadas: Como estão distribuídas as espécies agrupadas sob o nome de tauari na Amazônia? É possível definir a área de distribuição geográfica dessas espécies? Existem diferenças de abundância entre populações? É possível caracterizar a estrutura diamétrica dessas populações?

\section{Materiais e métodos}

Foram selecionadas seis áreas, com o fim de amostrar o grupo tauari em escala amazônica: três de institutos de pesquisas (IP) de manejo florestal e três de empresas madeireiras (EM). Esta seleção foi embasada: 1) na localização, de modo a amostrar diferentes regiões do bioma amazônico; e 2) na existência de inventários incluindo a localização das árvores de tauari com suas respectivas medidas de DAP. Das seis áreas selecionadas, uma está localizada em Sinnamary (Guiana Francesa - GF), na Amazônia setentrional, e as demais estão distribuídas do norte de Manaus até o sul de Belém (Fig. 1), abrangendo assim também regiões da Amazônia central e oriental. Ao todo, foram 401,25 ha inventariados, dos quais 51,25 ha em áreas de pesquisa florestal e 350 ha em áreas de empresas madeireiras. $\mathrm{O}$ tamanho das áreas variou de 3 a 43,75 ha para as áreas de pesquisa e de 100 a 150 ha para as áreas madeireiras.

Os parâmetros ambientais (pluviosidade, clima e topografia) das áreas estudadas estão descritos em Costa \& Magnusson (2003), Higuchi (2003) e Ferreira et al. (2006) para Manaus-AM [IP]; Costa et al. (2007) para Belterra-PA [IP]; e Gourlet-Fleury et al. (2004) para Sinnamary-GF [IP]. Para as áreas de madeireiras, estão descritos por Sebbenn et al. (2008) para Belterra-PA [EM], Smartwood \& Imaflora (2005) para Itacoatiara-AM [EM] e Francez et al. (2007) e Hirai et al. (2007) para Paragominas-PA [EM].

Descrição das áreas de pesquisa $(D A P \geq 10 \mathrm{~cm})$

Manaus-AM [IP] - Estação Experimental de Silvicultura Tropical (Projeto Bionte; EEST-ZF-2, do Instituto Nacional de Pesquisas da Amazônia -

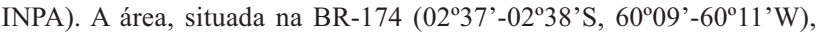
conta com três parcelas quadradas próximas, não exploradas, de 1 ha cada, em platô. 


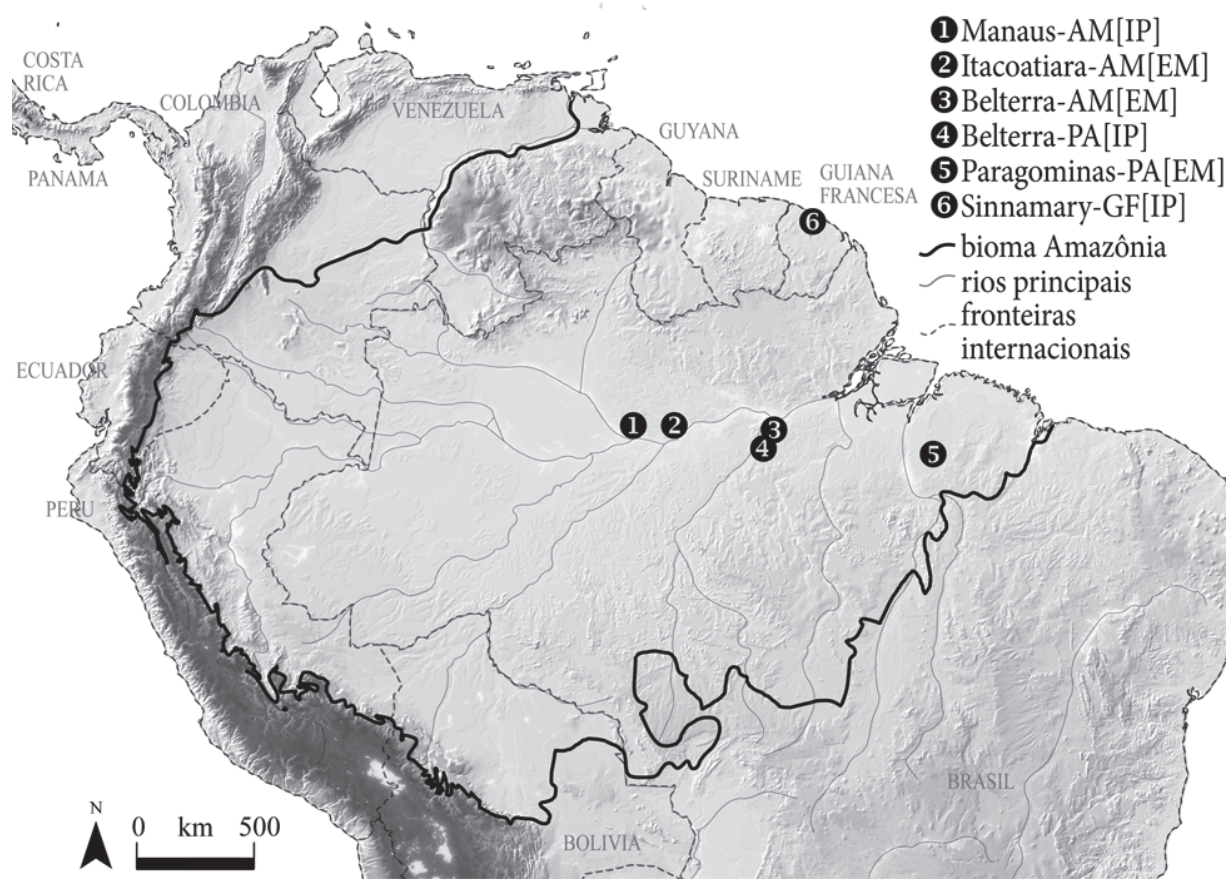

Figura 1. Localização das áreas selecionadas para este estudo (Mapa do bioma adaptado de PNUMA \& OTCA 2008; relevo adaptado do GTOPO30, cortesia U.S. Geological Survey).

Belterra-PA [IP] - Floresta Nacional Tapajós (Projeto Bom Manejo; Empresa Brasileira de Pesquisa Agropecuária - EMBRAPA Amazônia Oriental). Aárea, situada no Km 67 da BR-163 (253’S, 5455’W), próxima a Belterra, conta com 18 parcelas quadradas próximas, não exploradas, de 0,25 ha, somando 4,5 ha, em platô.

Sinnamary-GF [IP] - Estação experimental de Paracou (Centro de Cooperação Internacional em Pesquisas Agronômicas para o Desenvolvimento - CIRAD). A área estudada $\left(5^{\circ} 15^{\prime} \mathrm{N}, 52^{\circ} 55^{\prime} \mathrm{W}\right)$ conta com 13 parcelas quadradas próximas, não exploradas, 12 delas de 6,25 ha e uma de 25 ha, totalizando 43,75 ha, em platô, vertente e baixio.

\section{Descrição das áreas madeireiras $(D A P \geq 45 \mathrm{~cm})$}

Itacoatiara-AM [EM] - Fazenda Saracá da empresa Precious Woods-Mil Madeireira. A zona é localizada nos municípios de Itacoatiara e Silves $\left(2^{\circ} 43^{\prime}-3^{\circ} 04^{\prime} \mathrm{S}, 58^{\circ} 31^{\prime}-58^{\circ} 57^{\prime} \mathrm{W}\right)$. Para este estudo, foi verificado o inventário de uma área de 150 ha ( $250 \mathrm{~m} \mathrm{x} 400 \mathrm{~m})$, em platô, vertente e baixio, antes de sua exploração.

Belterra-PA [EM] - Área de exploração da empresa Maflops (no âmbito do Projeto Dendrogene-IBAMA-ITTO), situada na Floresta Nacional Tapajós, Km 83 da BR-163 ( $\left.2^{\circ} 45^{\prime} \mathrm{S}, 55^{\circ} 00^{\prime} \mathrm{W}\right)$, próxima a Belterra. Neste estudo, foi inventariada uma área quadrada de 100 ha, em platô, antes de sua exploração.

Paragominas-PA [EM] - Fazenda Rio Capim da empresa Cikel Brasil Verde, localizada no município de Paragominas, $250 \mathrm{~km}$ ao Sul de Belém, próximo à BR-010 $\left(3^{\circ} 35^{\circ} \mathrm{S}, 48^{\circ} 38^{\prime} \mathrm{W}\right)$, onde foi verificado o inventário de uma área quadrada de 100 ha, em platô, antes de sua exploração.

\section{Levantamento e análise dos dados}

Aárea de ocorrência das epécies de tauari está baseada na revisão das coleções de Allantoma, Cariniana e Couratari depositadas nos herbários amazônicos do Instituto Nacional de Pesquisas da Amazônia (INPA/AM), Museu Paraense Emílio Goeldi-(MG/PA), Embrapa Amazônia Oriental - (IAN/PA) e do IRD- Institut de Recherche pour le Développement - (CAY/Guiana Francesa) e no banco de dados de Lecythidaceae (The Lecythidaceae Pages - Mori \& Prance 2006).

A fim de estimar a área de distribuição de cada espécie, os registros foram mapeados. A área $A$ de distribuição das espécies foi delimitada pelo menor perímetro juntando todos os pontos de coleta (Fig. 2a-b). Esta delimitação foi feita sem considerar eventuais descontinuidades da área de distribuição dentro do bioma (presença de rios, montanhas, etc.).
Coletas com menos de $50 \mathrm{~km}$ de distância foram agrupadas em apenas um ponto, chamado de "zona de coleta". Em seguida, foi aplicado o princípio dos polígonos de Voronoi (Schulman et al. 2007): cada polígono (cuja superfície é denominada $A_{v}$ ) mostra o território mais próximo da "zona de coleta" que está dentro deste polígono (Fig. 2c) e permite identificar regiões onde coletas poderão melhorar a amostragem das populações. Depois disso, foi medida a maior distância $\left(d_{\text {isolamento }}\right)$ separando grupos de "zonas de coleta", pois qualquer conjunto de zonas de coleta pode ser separado em pelo menos dois grupos segundo a premissa de que cada zona do primeiro grupo fique a mais que $x \mathrm{~km}$ dos pontos do outro grupo. O maior valor para $x$ capaz de criar dois grupos corresponde à distância $d_{\text {isolamento }}($ Fig. 2a-b). Esta distância indica uma população disjunta ou falta de coletas. Assim, quando a $d_{\text {isolamento }}$ foi superior $1000 \mathrm{~km}$, as áreas foram classificadas como disjuntas. Por outro lado, a distância média $d_{\text {próxima }}$ à zona de coleta mais próxima foi calculada a fim de retratar a continuidade da população. $\mathrm{Na}$ Fig. 3a, a distância entre os pontos de coleta foram destacadas em cinza, sendo mais forte o tom de cinza quanto menor a distância entre os pontos.

A probabilidade das espécies ocorrerem onde não houve coletas foi simbolizada em mapas com base em duas premissas: no caso geral, 1 - em um dado território, a probabilidade de encontrar uma espécie aumenta com o número de zonas de coleta desta espécie em volta deste território, e 2 - quanto maior a distância do local de coleta, mais duvidosa a presença da espécie (Schulman et al. 2007).

O levantamento nas parcelas consistiu na verificação dos inventários botânicos realizados pelas instituições de manejo e atualização das identificações botânicas nas bases de dados. As árvores inventariadas como "tauari" e seus derivados (tauari-cachimbo, tauari-branco, etc.) foram verificadas sob seus aspectos dendrológicos e sua identificação confirmada com a coleta de material botânico quando necessário. Não foi descartada a possibilidade de que outros nomes locais também tivessem sido usados para essas espécies, por isso todas as árvores pertencentes aos gêneros Allantoma, Cariniana e Couratari foram verificadas.

O material botânico coletado foi determinado, registrado e depositado nos herbários amazônicos. Exsicatas com identificação dúvida foram verificadas pelo especialista da família junto à coleção do INPA. Após a atualização da base de dados, foram analisados, para cada área, os seguintes parâmetros, com comparações intra e interespecíficas das populações (teste H de Kruskal-Wallis, teste U de Mann-Whitney): 1- Riqueza em espécies de tauari - definida como o número de espécies deste grupo em cada área 


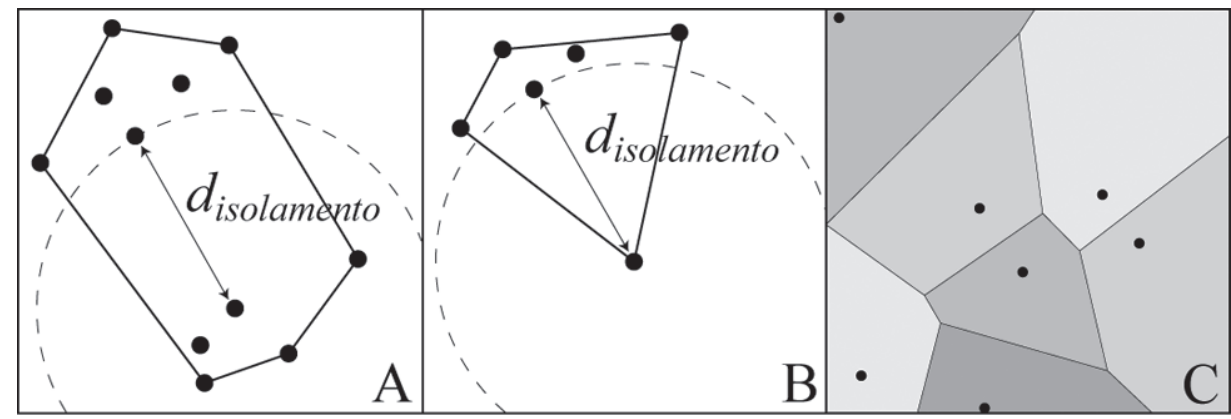

Figura 2. A, B) Dois casos de definição do $d$ ․ e da área de distribuição estimada através da determinação do menor perímetro contendo todas as zonas de coletas. C) Diagramas de Voronoi: polígono em volta de uma zona de coleta corresponde ao território mais próximo desta zona.

inventariada; 2- Abundância - estimada pela densidade absoluta $\mathrm{D}_{\text {abs }}=\mathrm{N}_{1} /$ $\mathrm{n}_{\mathrm{a}}$, sendo $\mathrm{N}_{i}$ o número total de indivíduos de uma espécie $i$ e $\mathrm{n}_{\mathrm{a}}$ a unidade de área, dada em indivíduos/hectare (ind./ha), e densidade relativa $\mathrm{Dr}=100$ $(\mathrm{N} / \mathrm{N})$, dada pela porcentagem de indivíduos de cada espécie pelo total de indivíduos de todas as espécies (Pires-O’Brien \& O’Brien 1995) do grupo tauari; 3- Área basal - Л(DAP/2) ${ }^{2}$, dada $\mathrm{em} \mathrm{m}^{2} /$ ha (Brower et al. 1997); 4- Estrutura diamétrica - distribuição dos indivíduos por classe diamétrica e 5- Diâmetro máximo -por espécies, em centímetros.

\section{Resultados}

Composição especifica do grupo tauari

O levantamento nos herbários indicou a ocorrência de 16 espécies do grupo tauari na Amazônia, 12 pertencentes ao gênero Couratari, três ao Allantoma e uma ao Cariniana; Couratari prancei, no Acre, e C. sandwithii, na Venezuela, Guiana e Suriname, não possuem nome vernacular registrado, mas podem ser confundidas com as demais (Mori \& Prance 1990) e por isso também foram incluídas (Tab. 1).

$\mathrm{O}$ conjunto das seis áreas de estudo corresponde às regiões onde já existiam registros de coleta de 14 das 16 espécies (Fig. 1 e 3). Após a verificação dos inventários, nove das 14 espécies foram encontradas, sete delas pertencentes ao gênero Couratari, uma ao Allantoma e outra ao Cariniana (Tab. 2). Couratari tauari foi encontrada apenas no entorno das parcelas de estudo de Belterra-PA [IP], sendo assim registrada pela primeira vez a ocorrência desta espécies fora da sua região de distribuição conhecida (Fig. 3i). Couratari guianensis, C. stellata e C. oblongifolia foram encontradas em quatro das seis áreas estudadas. No entanto, $C$. guianensis foi observada nas proximidades das parcelas das seis áreas, embora esta observação não tenha sido considerada nos cálculos. Couratari multiflora foi encontrada apenas em duas áreas, Manaus-AM [IP] e Sinnamary-GF [IP] (Tab. 2).

A heterogeneidade dos desenhos das parcelas estudadas e dos DAP de inventários impossibilitou a comparação da riqueza entre as áreas. No entanto, o grupo de espécies encontradas em cada área nunca foi o mesmo, até entre as duas áreas próximas em Belterra. Os altos números de espécies apareceram tanto em pequenas como em grandes áreas, mostrando a ausência de relação entre riqueza e tamanho amostral (Tab. 2).

\section{Área de distribuição geográfica}

Para construir os mapas (Fig. 3), foram examinadas 1426 exsicatas de herbários disponíveis para as 16 espécies, das quais um terço são registros de Couratari guianensis. Após o agrupamento das coletas no raio de até $50 \mathrm{~km}$ de distância, 382 zonas de coleta foram definidas, delimitando uma área total superior a 4,5 milhões de $\mathrm{km}^{2}$. A distribuição geográfica das zonas de coleta é altamente heterogênea, com a maioria das coletas concentrada na região do Acre e no seu entorno, ao longo da BR-319, no entorno de Manaus e de Belém e na região das Guianas (Fig. 3a-b). As regiões do sudeste da Amazônia, das bacias dos rios Purus, Juruá, Negro até o sul da Colômbia, por outro lado, se destacam pelo baixo número de coletas.

No nível específico, as áreas $A$ variaram consideravelmente: cerca de $900 \mathrm{~km}^{2}$ para Couratari calycina até cerca de 4 milhões de $\mathrm{km}^{2}$ para $C$. guianensis, englobando a área de distribuição de todas as espécies de tauari, exceto de C. macrosperma, que ocorre também na Mata Atlântica. Couratari guianensis, que se estende até a Costa Rica, e $C$. macrosperma, são as únicas que também ocorrem fora da Amazônia. No entanto, devido a barreiras ecológicas (norte de cadeia andina para C. guianensis e cerrados extensos para C. macrosperma), as populações extra-amazônicas foram desconsideradas neste estudo.

Algumas espécies de Couratari (C. atrovinosa, C. macrosperma, $C$. stellata e $C$. sandwithii) tiveram sua área $A$ disjunta, com zonas de coleta (ou conjuntos de zonas) separadas das demais dentro desta área $A$, o que foi ilustrado por altos valores de $A_{v}\left(>200\right.$ milhões $\left.\mathrm{km}^{2}\right)$ e de $d_{\text {isolamento }}(>1000$ $\mathrm{km}$, inclusive para C. sandwithii) (Tab. 3).

Os mapas e as características das áreas de distribuição específicas permitem distinguir quatro tipos de distribuição: pan-amazônica (Fig. 3c; Tab. 3), ampla (Fig. 3d-i; Tab. 3), regional (Fig. 3j-m; Tab. 3) e endêmica (Fig. 3n-p; Tab. 3). Couratari guianensis foi observada em quase toda a Amazônia e com a menor distância $d_{\text {isolamento }}(\approx 325 \mathrm{~km})$ das espécies com $A>1$ milhão de $\mathrm{km}^{2}$, sendo sua área de distribuição classificada como pan-amazônica contínua.

Seis espécies apresentam ampla área de distribuição; dentre elas, Couratari stellata e C. macrosperma são disjuntas. Todas mostram regiões com maiores concentrações de 
Tabela 1. Espécies de tauari ocorrentes na Amazônia (Prance \& Mori 1979; Mori \& Prance 1990; Mori \& Lepsch-Cunha 1995; Gourlet-Fleury et al. 2004; Mori \& Prance 2006), apontando aquelas inventariadas neste estudo e as citadas no comércio (ITTO 2005; IBAMA 2006; 2007; AIMEX 2008), indicando a categoria e critérios de ameaça segundo a IUCN (2009 - versão 2.3).

\begin{tabular}{|c|c|c|c|c|c|}
\hline Espécies ocorrentes no bioma Amazônia & Nomes vernaculares & $\begin{array}{l}\text { Espécies inventariadas } \\
\text { neste estudo }\end{array}$ & $\begin{array}{l}\text { Espécies citadas } \\
\text { pelo comércio }\end{array}$ & $\begin{array}{l}\text { Categoria de } \\
\text { Ameaça }\end{array}$ & $\begin{array}{l}\text { Critérios } \\
\text { de ameaça }\end{array}$ \\
\hline $\begin{array}{l}\text { Allantoma decandra (Ducke) S.A. Mori, } \\
\text { Y.-Y. Huang \& Prance* }\end{array}$ & tauari, tauari vermelho (Brasil) & $X$ & $\mathrm{X}$ & & \\
\hline $\begin{array}{l}\text { Allantoma integrifolia (Ducke) S.A. } \\
\text { Mori, Y.-Y. Huang \& Prance* }\end{array}$ & $\begin{array}{l}\text { tauari, jequitibá do Amazonas } \\
\text { (Brasil) }\end{array}$ & & $\mathrm{X}$ & Vulnerável & $\mathrm{B} 1+2 \mathrm{c}$ \\
\hline $\begin{array}{l}\text { Allantoma pauciramosa (W.A. Rodrigues) } \\
\text { S.A. Mori, Y.-Y. Huang \& Prance* }\end{array}$ & tauari (Brasil) & & & Em perigo & $\mathrm{B} 1+2 \mathrm{c}$ \\
\hline Cariniana micrantha Ducke & $\begin{array}{l}\text { castanha-de-macaco, tauari, } \\
\text { tauari-vermelho, jequitibá-rosa e } \\
\text { castanha-vermelha (Brasil) }\end{array}$ & $\mathrm{X}$ & $X$ & Não avaliada & \\
\hline Couratari atrovinosa Prance & tauari (Brasil) & & & Em perigo & $\mathrm{B} 1+2 \mathrm{~d}$ \\
\hline Couratari calycina Sandwith & maho-cigare (Guiana Francesa) & $\mathrm{X}$ & & Vulnerável & D2 \\
\hline Couratari gloriosa Sandwith & maho-cigare (Guiana Francesa) & & & Não avaliada & \\
\hline Couratari guianensis Aubl. & $\begin{array}{c}\text { tauari, tauari-branco, cachimbeiro } \\
\text { (Brasil), maho-cigare (Guiana } \\
\text { Francesa) }\end{array}$ & $X$ & $\mathrm{X}$ & Vulnerável & A2bcde \\
\hline Couratari longipedicellata W.A. Rodrigues & tauari (Brasil) & $\mathrm{X}$ & & Vulnerável & $\mathrm{B} 1+2 \mathrm{c}, \mathrm{D} 1$ \\
\hline Couratari macrosperma A.C. Sm. & tauari (Brasil) & & $\mathrm{X}$ & Não avaliada & \\
\hline Couratari multiflora (Sm.) Eyma & $\begin{array}{l}\text { tauari (Brasil), maho-cigare } \\
\text { (Guiana Francesa) }\end{array}$ & $\mathrm{X}$ & $\mathrm{X}$ & Não avaliada & \\
\hline $\begin{array}{l}\text { Couratari oblongifolia } \\
\text { Ducke \& R. Knuth }\end{array}$ & $\begin{array}{l}\text { tauari, tauari-branco (Brasil), } \\
\text { maho-cigare (Guiana Francesa) }\end{array}$ & $\mathrm{X}$ & $\mathrm{X}$ & Não avaliada & \\
\hline Couratari prancei W.A. Rodrigues & - & & & $\begin{array}{l}\text { Criticamente } \\
\text { em perigo }\end{array}$ & $\mathrm{B} 1+2 \mathrm{~d}$ \\
\hline Couratari sandwithii Prance & - & & & Vulnerável & D2 \\
\hline Couratari stellata A.C. Sm. & $\begin{array}{l}\text { tauari (Brasil), maho-cigare } \\
\text { (Guiana Francesa) }\end{array}$ & $\mathrm{X}$ & $\mathrm{X}$ & Não avaliada & \\
\hline Couratari tauari O. Berg & tauari (Brasil) & & $\mathrm{X}$ & Vulnerável & D2 \\
\hline
\end{tabular}

* Antes citada como Cariniana

coleta: Allantoma decandra e C. macrosperma, no oeste e no sudoeste da Amazônia, respectivamente, e C. multiflora e $C$. oblongifolia, no nordeste e leste do bioma. Couratari stellata distinguiu-se por ocorrer em todas as grandes regiões: central, setentrional, meridional, ocidental e oriental, mas apresenta grandes áreas sem coletas $\left(A_{v}\right.$ média $=35.590 \mathrm{~km}^{2}$, maior valor dentre as 16 espécies; Fig. $3 \mathrm{~d}$ ). Ao contrário, $C$. macrosperma, embora tivesse duas zonas de coleta remotas (norte e leste da Amazônia), mostrou a distribuição mais agregada em uma área, ilustrada pelo menor valor $d$ das espécies de distribuição maior que 1 milhão de $\mathrm{km}^{2}$ (96xima km vs. 197 km para C. stellata; Fig. 3g).

Entre as espécies de distribuição regional $(A<500.000$ $\mathrm{km}^{2}$ ), Couratari sandwithii e C. atrovinosa se destacam pelo isolamento das coletas. As demais espécies (C. calycina e C. longipedicellata) mostraram distribuição endêmica, com áreas $A$ inferiores a $10.000 \mathrm{~km}^{2}$.

\section{Abundância e estrutura diamétrica}

A maior densidade absoluta de árvores do grupo tauari foi encontrada em Belterra-PA [IP] e a menor em SinnamaryGF [IP], considerando as árvores com $\mathrm{DAP} \geq 10 \mathrm{~cm}$ nas três áreas de pesquisa (respectivamente, 14,44 e 5,58 ind./ha), ou as árvores com $\mathrm{DAP} \geq 45 \mathrm{~cm}$ em todas as áreas $(2,44 \mathrm{e}$
0,21 ind./ha) (Tab. 2). A média variou em torno de 0,86 ind./ ha, com desvio padrão de 0,85 ind./ha (DAP $\geq 45 \mathrm{~cm})$. Não foi evidenciada correlação entre a variação da abundância do grupo e a variação das riquezas locais em espécies de tauari (coeficiente de correlação de Spearman $\rho=0,289$; $\mathrm{P}=0,49 ; \mathrm{n}=6)$.

A variação das abundâncias locais do grupo resultou das diferenças de abundâncias locais das espécies. Assim, no conjunto das áreas de pesquisa (DAP $\geq 10 \mathrm{~cm})$, a média das densidades absolutas foi de 2,64 ind./ha com desvio padrão de 4,39. Este desvio padrão, junto com a baixa mediana de 0,57 ind./ha, reflete a dominância de uma espécie em cada uma das áreas. Por exemplo, a densidade total de árvores de tauari em Manaus-AM [IP] é de 6,33 ind./ha, sendo que Couratari stellata, com 5,33 ind./ha, foi a espécie dominante em relação à Cariniana micrantha, Couratari longipedicellata e C. multiflora. Este padrão de dominância ocorreu também no conjunto das áreas das empresas madeireiras (DAP $\geq 45$ $\mathrm{cm})$, onde a mediana das densidades específicas (0,05 ind./ ha) foi muito abaixo da média (0,20 ind./ha, desvio-padrão 0,32 ind./ha), devido às espécies dominantes (Fig. 4).

Três espécies apresentaram abundâncias relativamente altas, densidades acima de 4 ind./ha com DAP $\geq 10 \mathrm{~cm}$ para Couratari stellata e C. multiflora, e acima de 0,4 ind./ha 


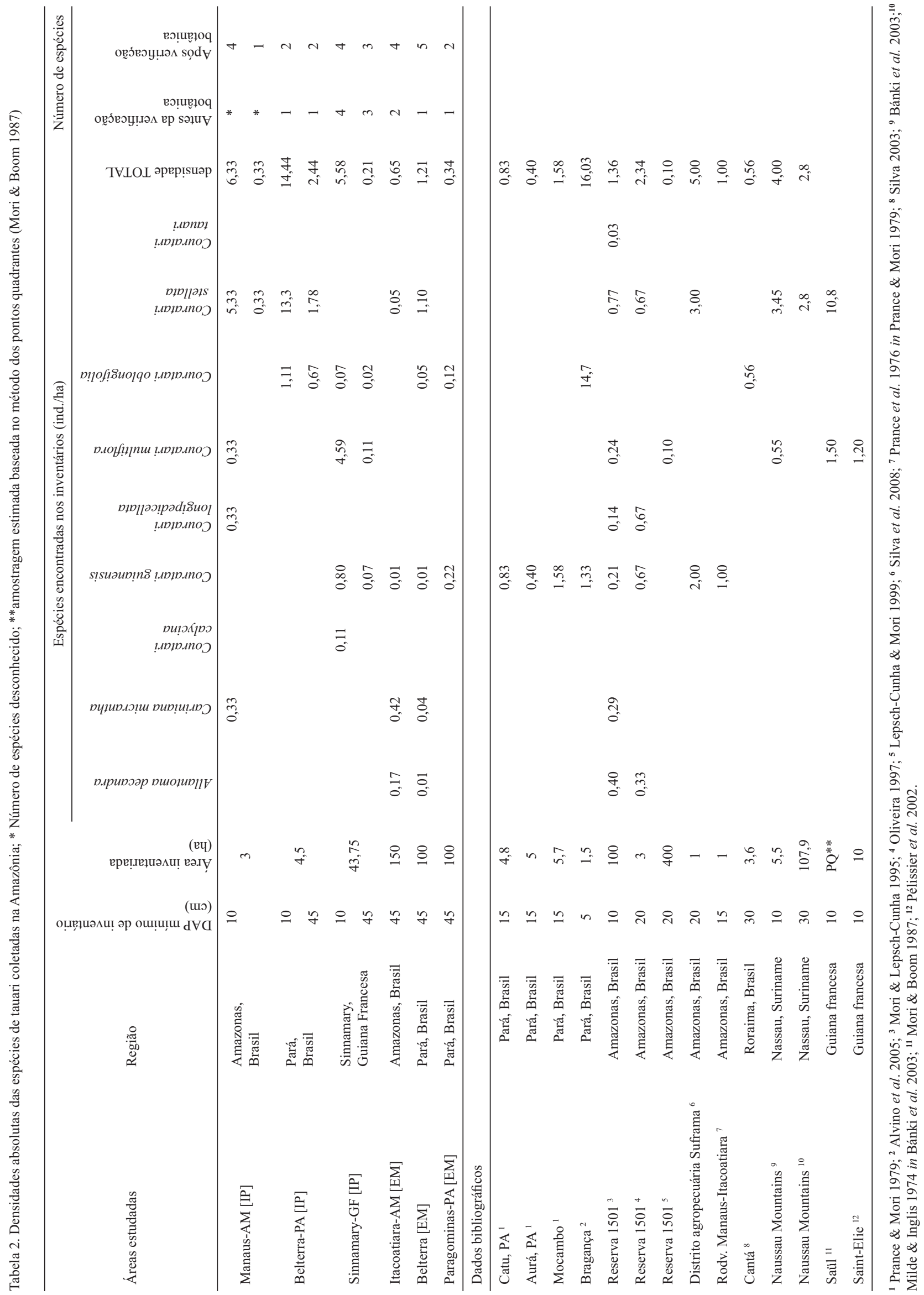


Tabela 3. Distribuição geográfica. $\boldsymbol{N}$ - número de coletas; $\boldsymbol{N}$ '- número de zonas de coletas; $\boldsymbol{A}$ - área de distribuição $\left(\mathrm{km}^{2}\right) ; \boldsymbol{A}$ - superfície média dos polígonos de Voronoi $\left(\mathrm{km}^{2}\right) ; \boldsymbol{A}_{v \text { max }}$ - superfície do maior polígono $\left(\mathrm{km}^{2}\right) ; \boldsymbol{d}$ (km; em negrito, $\boldsymbol{d}$ $>1000 \mathrm{~km}) ; \boldsymbol{d}_{\text {próxima }}(\mathrm{km}) ;$ * coletas fora do bioma Amazônia foram descartadas.

\begin{tabular}{|c|c|c|c|c|c|c|c|c|c|}
\hline Espécies & $N$ & $N^{\prime}$ & $A$ & $\begin{array}{l}A_{v} \text { média } \\
\left(A / N^{\prime}\right)\end{array}$ & $A_{v} \max$ & $d_{\text {isolamento }}$ & $d_{\text {próxima }}$ & Padrão de distribuição & $\begin{array}{l}\text { Continuidade da } \\
\text { distribuição }\end{array}$ \\
\hline Couratari guianensis $*$ & 461 & 113 & 4057286 & 35905 & 155582 & 325 & 155 & Pan-amazônica & Contínua \\
\hline Couratari stellata & 237 & 33 & 2500132 & 75762 & 274029 & 1158 & 197 & Amplo & Disjunta \\
\hline Couratari multiflora & 157 & 42 & 2111533 & 50275 & 190367 & 656 & 161 & Amplo & Contínua \\
\hline Allantoma decandra & 140 & 36 & 1387246 & 38535 & 136406 & 500 & 116 & Amplo & Contínua \\
\hline Couratari macrosperma* & 142 & 29 & 1326646 & 45746 & 374346 & 1103 & 96 & Amplo & Disjunta \\
\hline Cariniana micrantha & 56 & 24 & 1285623 & 53568 & 159663 & 563 & 153 & Amplo & Contínua \\
\hline Couratari oblongifolia & 86 & 35 & 801803 & 23582 & 85151 & 519 & 100 & Amplo & Contínua \\
\hline Couratari atrovinosa & 16 & 6 & 425839 & 70973 & 234136 & 1528 & 62 & Regional & Disjunta \\
\hline Couratari tauari & 26 & 9 & 142681 & 15853 & 36047 & 700 & 166 & Regional & Contínua \\
\hline Couratari gloriosa & 40 & 6 & 52768 & 8795 & 18854 & 365 & 137 & Regional & Contínua \\
\hline Couratari sandwithii & 4 & 3 & 15486 & & & 1256 & 55 & Regional & Disjunta \\
\hline Couratari longipedicellata & 23 & 6 & 6419 & 1070 & 3256 & 214 & 64 & Endêmico & \\
\hline Allantoma integrifolia & 21 & 4 & 2751 & 688 & 1170 & 140 & 85 & Endêmico & \\
\hline Couratari calycina & 8 & 3 & 1224 & & & 113 & & Endêmico & \\
\hline Allantoma pauciramosa & 5 & 1 & & & & & & Endêmico & \\
\hline Couratari prancei & 6 & 1 & & & & & & Endêmico & \\
\hline
\end{tabular}

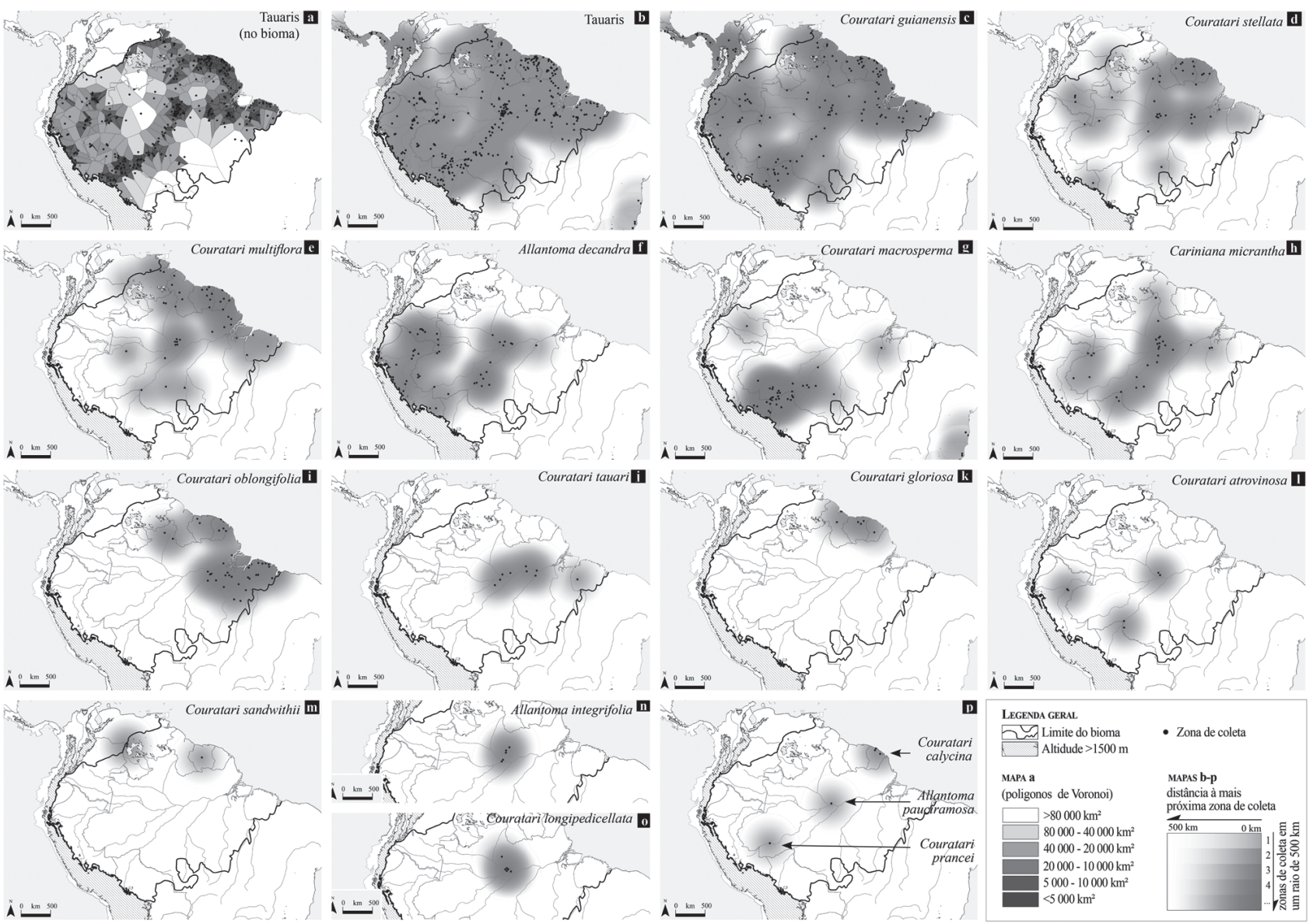

Figura 3. Distribuições das espécies de tauari a partir das zonas de coleta: a) esforço de coleta ilustrado com polígonos de Voronoï; b) todas as espécies; c) distribuição pan-amazônica; d-i) distribuição ampla; j-m) distribuição regional; n-p) distribuição endêmica. Bioma adaptado do PNUMA-OTCA (2008) 

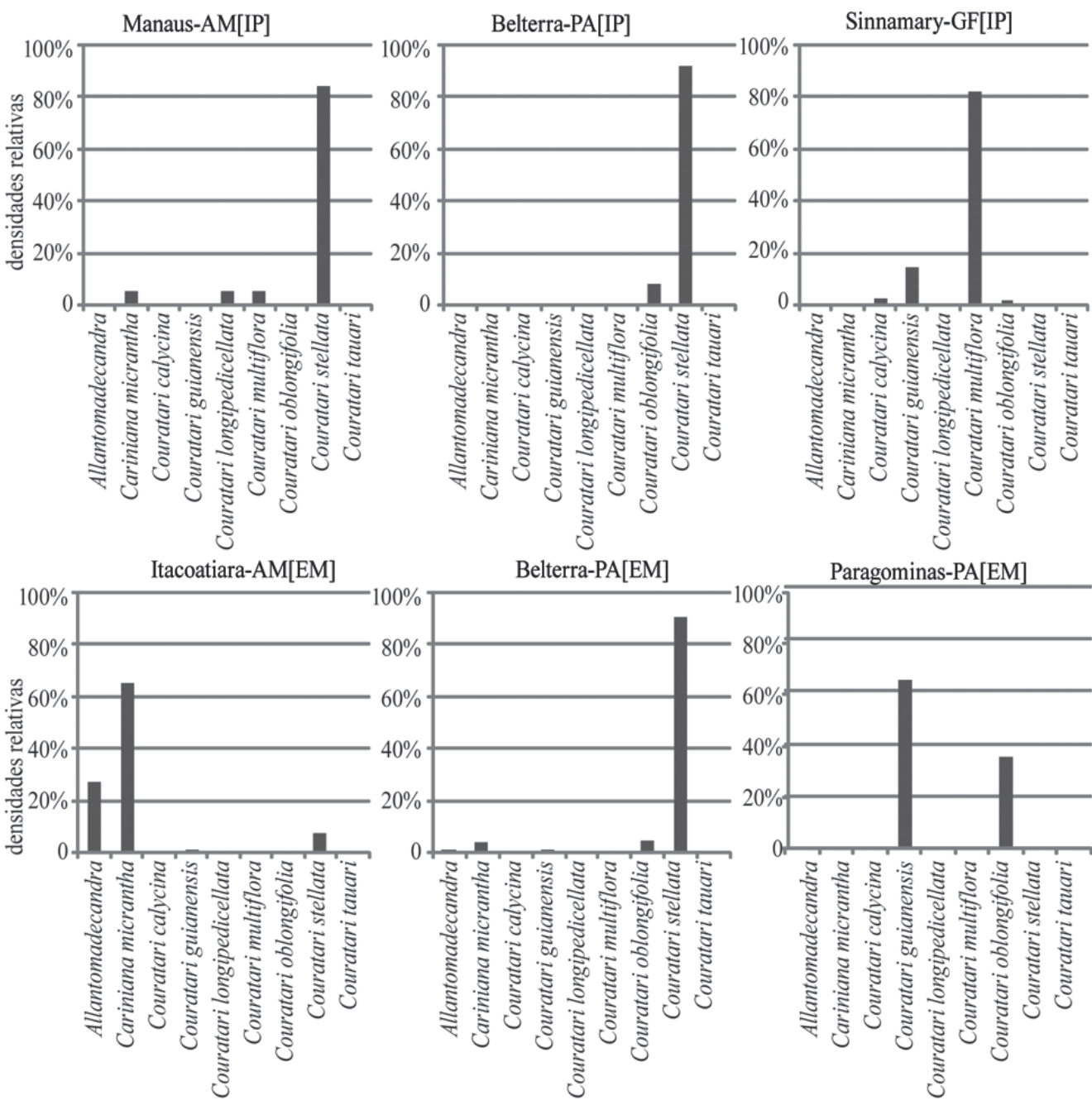

Figura 4. Estrutura diamétrica das populações de tauari $(\mathrm{N}>15)$ nas três áreas inventariadas a partir de $10 \mathrm{~cm}$ de DAP.

com DAP $\geq 45 \mathrm{~cm}$ para Cariniana micrantha (Tab. 2). A Fig. 4 compara as densidades relativas das espécies, mostrando que pelos menos $60 \%$ dos indíviduos de tauari pertencem a uma só espécie em todas as áreas e que, em quatro delas, essa proporção alcançou $80 \%$. Couratari stellata foi a dominante em três das quatro áreas onde ocorreu, Manaus-AM [IP], Belterra-PA [IP], Belterra-PA [EM], representando entre 89\% e $92 \%$ dos indivíduos inventariados de tauari, as três maiores taxas de dominância local do estudo. Couratari multiflora dominou em Sinnamary-GF [IP] (82\% dos indivíduos de tauari com DAP $\geq 10 \mathrm{~cm}$ ) e Cariniana micrantha em Itacoatiara-AM [EM] ( $65 \%$ dos indivíduos de tauari com DAP $\geq 45 \mathrm{~cm})$. Couratari oblongifolia e $C$. guianensis apresentaram densidades baixas, com máximas próximas a 1 ind./ha (considerando $\mathrm{DAP} \geq 10 \mathrm{~cm}$ ). As demais espécies foram ainda mais escassas, particularmente as espécies com distribuição endêmica: $C$. longipedicellata e C. calycina (Tab. 2).

A baixa abundância das espécies (densidade menor que 1 ind./ha) somada ao pequeno tamanho amostral das áreas de pesquisa limitou o estudo das estruturas diamétricas (DAP $>10$ $\mathrm{cm})$ a quatro populações de Couratari: uma de C. guianensis, uma de C. multiflora e duas de C. stellata (Fig. 5). Couratari stellata e $C$. multiflora apresentaram estruturas semelhantes, mostrando um nítido padrão "J-reverso", estando o maior número de indivíduos presentes nas menores classes $(10$ a $30 \mathrm{~cm})$ enquanto $C$. guianensis mostrou uma estrutura mais homogênea entre as classes (Fig. 5). Apesar da dominância de indivíduos na menor classe de $C$. stellata, sua abundância foi três vezes maior na população de Belterra-PA [IP], com representantes em todas as classes diamétricas. Na população de Manaus-AM [IP], a maior parte dos indivíduos não ultrapassou a classe de $\mathrm{DAP}=30$ $\mathrm{cm}$, com ausência de representantes nas classes $\mathrm{DAP}=50,70$ e $80 \mathrm{~cm}$ (Fig. 5). A população de C. multiflora Sinnamary-GF [IP], baseada também em indivíduos até a classe $\mathrm{DAP}=30 \mathrm{~cm}$ apareceu dominando em densidade cada classe diamétrica da população de C. guianensis da mesma área.

Caracterização dos DAP e área basal

No campo, foi observado que Cariniana micrantha, Couratari stellata e C. oblongifolia alcançam DAP maiores 
Couratariguianensis Couratarimultiflora Courataristellata Courataristellata SINNAMARY-GF[IP] SINNAMARY-GF[IP] MANAUS-AM[IP] BELTERRA-PA[IP]
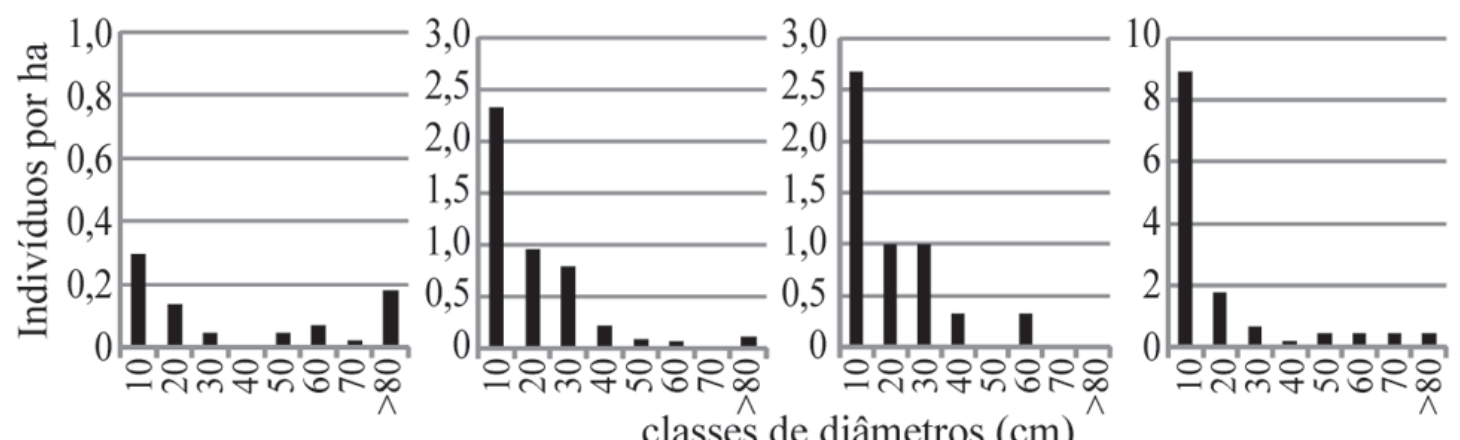

Figura 5. Densidades relativas das espécies nas áreas estudadas.

do que os anteriormente registrados para estas espécies, em particular C. stellata $(175 \mathrm{~cm} v s .80 \mathrm{~cm})$. Com base nas medianas dos DAP das populações, foi feita uma classificação das espécies nas áreas madeireiras: Cariniana micrantha $\mathrm{e}$ Couratari oblongifolia $(\mathrm{DAP}=80 \mathrm{~cm})>C$. stellata $(\mathrm{DAP}=$ $77 \mathrm{~cm})>C$. guianensis $(\mathrm{DAP}=55 \mathrm{~cm})>$ Allantoma decandra $(\mathrm{DAP}=54 \mathrm{~cm})$; esta última, porém com uma árvore de $\mathrm{DAP}=190 \mathrm{~cm}$ encontrada em Belterra-PA [EM]. Nas áreas de pesquisa, a maior espécie foi Couratari oblongifolia $(\mathrm{DAP}=51 \mathrm{~cm})$, seguida por $C$. guianensis $(\mathrm{DAP}=28 \mathrm{~cm})$ e $C$. stellata $(\mathrm{DAP}=19 \mathrm{~cm})$, e as duas menores foram $C$. multiflora $(\mathrm{DAP}=20 \mathrm{~cm})$ e $C$. calycina $(\mathrm{DAP}=15 \mathrm{~cm})$. No caso de $C$. stellata nas áreas de pesquisa, a baixa mediana dos DAP é resultado da grande proporção de árvores na primeira classe (DAP = 10-20 cm; Fig 6).

A maior área basal foi observada para Couratari stellata na região de Belterra-PA $\left(0,701\right.$ a $1,255 \mathrm{~m}^{2} /$ ha; DAP $\geq 45$ $\mathrm{cm})$, onde esta espécie ocorreu com alta densidade $(1,1$ ind./ha, DAP $\geq 45 \mathrm{~cm}$ ) e apresentou quase $50 \%$ de árvores de $\mathrm{DAP} \geq 80 \mathrm{~cm}$.

\section{Verificação dos inventários das áreas estudadas}

Em três das seis áreas, foram encontradas pelo menos duas vezes mais espécies do que o previsto (Tab. 2). Por consequência, as abundâncias reais das espécies de tauari foram inferiores às abundâncias esperadas com base nos inventários preliminares, limitando assim as análises.

As áreas madeireiras estudadas comercializam oficialmente sob o nome "tauari" Cariniana micrantha e Couratari guianensis, C. oblongifolia e C. stellata (AIMEX 2008; Smartwood \& Imaflora 2005). Neste estudo, quatro outras espécies de tauari, Allantoma decandra, Couratari calycina, C. longipedicellata e C. tauari, foram observadas, sendo a última encontrada somente no entorno das parcelas inventariadas. Nas áreas de pesquisa, duas outras espécies foram encontradas como tauari: Couratari calycina e $C$. longipedicellata.

Tanto nas áreas de pesquisa como nas madeireiras, a composição das comunidades de tauari mudou após a verificação dos inventários que antecederam este estudo. Em Belterra-
PA [IP], a única espécie inicialmente listada era Couratari oblongifolia, porém 93\% dos indivíduos correspondem a $C$. stellata (Fig. 4). Em Sinnamary-GF [IP], o inventário inicial identificou $99 \%$ dos espécimes como C. multiflora, porém verificou-se que apenas $82 \%$ pertencem a esta espécie (Fig. 4). Couratari gloriosa, inicialmente citada, não foi encontrada e uma espécie a mais, C. calycina, foi identificada. Em Paragominas-PA [EM], todos os espécimes de tauari haviam sido identificados como Couratari guianensis, porém 35\% destes são de fato C. oblongifolia. Em Belterra-PA [EM], cuja lista comercial descreveu tauari como C. oblongifolia, possui $90 \%$ dessas árvores correspondendo à $C$. stellata, e as demais pertencendo a quatro espécies (Tab. 2). Em Itacoatiara-AM [EM], os espécimes de tauari foram identificados como Cariniana micrantha e Couratari guianensis, mas as duas espécies representam apenas $65 \%$ e $1 \%$ dos espécimes de tauari, respectivamente, as demais correspondem às espécies Allantoma decandra (25\%) e Couratari stellata (7\% ; Fig. 4). Cariniana micrantha recebeu ainda outros dois nomes: castanha-de-macaco em Manaus-AM [IP] e tauari-vermelho em Itacoatiara-AM [EM].

\section{Discussão}

O número de espécies de tauari nas áreas de estudo refletiu o padrão geral esperado a partir do levantamento nos herbários (Fig. 3c-p), sendo maior em três regiões: em torno de Manaus, na bacia do rio Madeira e na Guiana Francesa (Fig. $3 b$ ). Tais regiões são conhecidas por sua riqueza florística (ter Steege et al. 2003a), explicada por várias teorias (e.g., teoria dos refúgios, Prance 1982; Haffer \& Prance 2002; no caso de Manaus, pela confluência de domínios fitogeográficos, Oliveira 1997; qualidade dos solos e pluviosidade regional, ter Steege et al. 2003a).

Mori \& Prance (1990) sugeriram que a maior riqueza florística nas áreas das Guianas e da Amazônia central estaria sendo superestimada pelo maior esforço amostral nessas regiões. Portanto, mapas de distribuição devem considerar esta tendência. As regiões do bioma com menor número de 

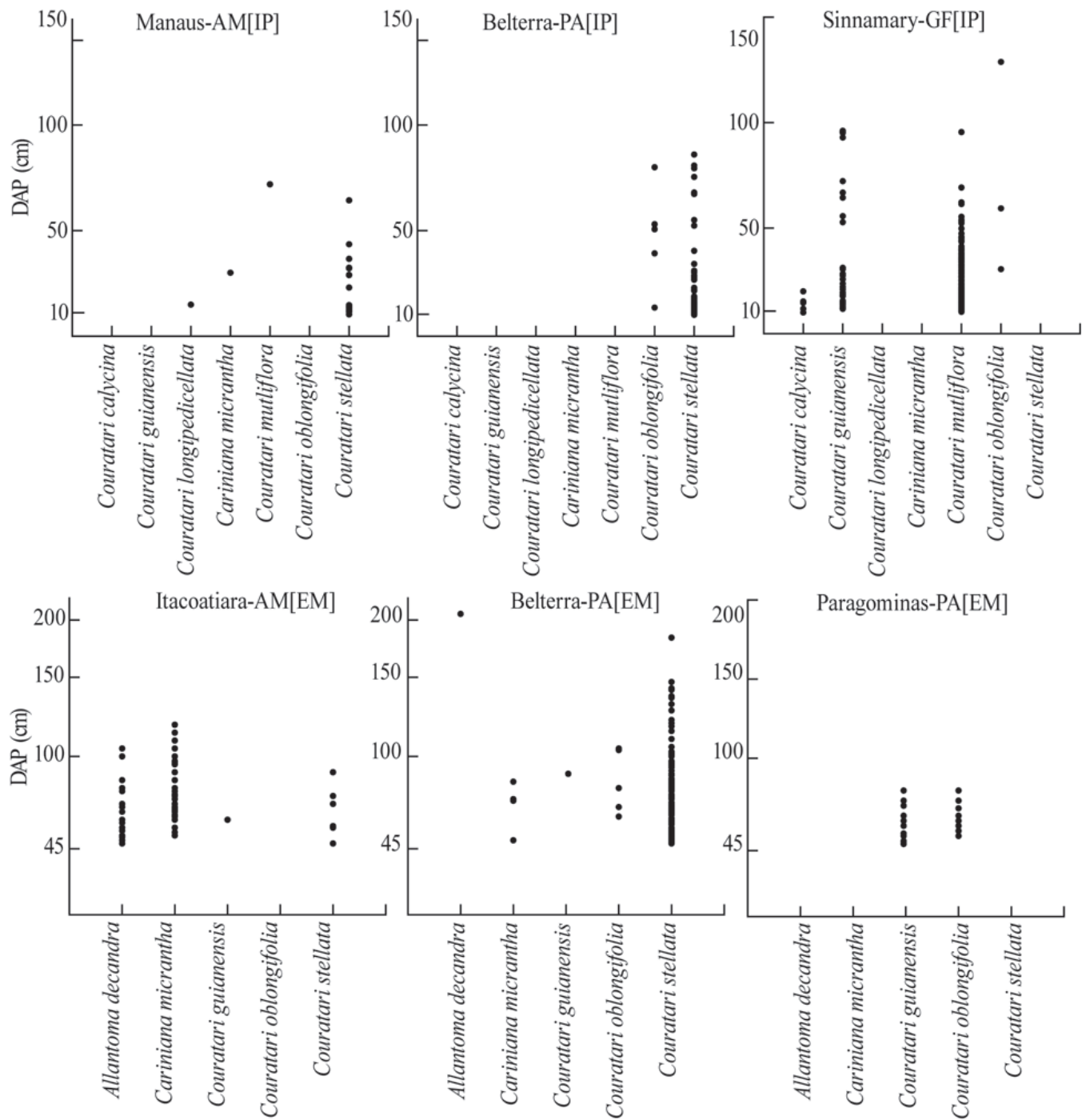

Figura 6. Distribuição dos DAP das espécies de tauari nas áreas estudadas.

espécies de tauari são o sudeste da Amazônia, as bacias dos rios Purus e Negro até o sul da Colômbia (Fig. 3a-b) e correspondem, também, a regiões com lacunas de coleta (Hopkins 2007). As áreas de distribuição de todas as espécies de tauari mostraram ausências ou poucas coletas justamente nessas regiões (Fig. 3a-b), inclusive para Couratari guianensis, com distribuição pan- e extra-amazônica. Isso, somado às novas ocorrências de espécies pouco abundantes em regiões bem coletadas, como C. tauari na Flona Tapajós, corrobora as observações de Hopkins (2007) e Schulman et al. (2007), de que as áreas extrapoladas com base em amostras de herbário dependem ainda fortemente do esforço de coleta.

Embora os dados de ocorrência permaneçam fragmentados, as áreas de distribuição do tauari na Amazônia, junto com os dados de abundância e as propriedades de estrutura diamétrica das populações levantadas neste estudo, permitem propor uma caracterização do padrão de distribuição geográfica das espécies estudadas aqui, levando em conta as tendências mencionadas acima.
Couratari stellata apresentou uma distribuição ampla, com grandes áreas sem coleta e o maior índice $d_{\text {isolamento }}$. A espécie ocorreu com densidades de até 13,3 ind./ha com $\mathrm{DAP} \geq 10 \mathrm{~cm}$, e dominância local sobre as demais espécies de tauari. Quando considerados este estudo e outros inventários onde a espécie ocorreu (Mori \& Boom 1987, na Guiana Francesa; Mori \& Lepsch-Cunha 1995, na região de Manaus; Bánki et al. 2003, em duas áreas no Suriname; ter Steege et al. 2003b, no Suriname; Duque et al. 2003, perto de Caquetá, Colômbia; Salomão et al. 2007, na região do Xingu), C. stellata sempre aparece como dominante, exceto em Itacoatiara-AM [EM] e no Xingu. Os dados de Mori \& Boom (1987), Bánki et al. (2003) e ter Steege et al. (2003b) mostraram que $C$. stellata esteve também entre as dez espécies arbóreas mais abundantes, dominando não somente as demais espécies de tauari, mas também a comunidade arbórea como um todo. Essa observação, junto com a alta variação na abundância entre áreas próximas na região de Manaus ou na Guiana Francesa (Tab. 2), sugere que a 
espécie ocorra de forma agregada em escala regional, com abundâncias locais altas. Esse padrão explicaria a grande variação na abundância e as vastas áreas sem coleta dentro de sua extensa distribuição no bioma, retratando a dificuldade de se amostrar em escala amazônica uma espécie com ocorrência agregada. No entanto, a escassez de coletas não permite ainda descartar a possibilidade de uma distribuição geográfica fragmentada para C. stellata.

Couratari stellata se destacou das outras espécies de tauari pelo grande diâmetro de suas árvores, apresentando a maior área basal do grupo, o que concorda com as observações de Mori \& Boom (1987). Ela possui também a maior densidade da madeira de tauari $\left(0,65 \mathrm{~g} / \mathrm{cm}^{3}\right.$, Chave et al. $2006 ; 0,63 \mathrm{~g} / \mathrm{cm}^{3}$, IBAMA/LPF 2008) e está entre as duas espécies mais altas de Lecythidaceae (depois de Carinaiana micrantha; Mori \& Swarthout 2007). Tais características, juntamente com sua ampla distribuição e alta abundância em certas áreas, fazem de C. stellata uma espécie estruturante da floresta e um importante componente do dossel amazônico, mas também alvo do mercado madeireiro.

Couratari guianensis é a espécie de tauari mais coletada em toda a Amazônia, com o menor valor de $d_{\text {próximo }}$, permitindo uma extrapolação segura de sua área de distribuição, a qual abrange quase todo o bioma amazônico, chegando até a Costa Rica. Sua presença fica apenas duvidosa na região sudeste da Amazônia, cuja baixa amostragem florística já foi apontada por Hopkins (2007). Ela é a única espécie que coexiste com todas as demais espécies de tauari na Amazônia, sugerindo uma alta plasticidade fenotípica. Contudo, tanto neste estudo quanto na literatura, não há registros de altas densidades (até 2 ind./ha, DAP $\geq 20 \mathrm{~cm}$, área inventariada: 1 ha; Tab. 2). Ter Steege et al. (2003b) consideraram esta espécie ocasional na Guiana. Ao contrário de C. stellata, as numerosas zonas de coleta em toda a Amazônia e os valores mais homogêneos de abundância em relação às outras espécies de tauari, embora fracos, levam a considerar que esta espécie tem uma distribuição pan-amazônica não agregada.

Tal distribuição torna questionável a classificação de Couratari guianensis como espécie vulnerável com base no possível declínio de $30 \%$ de sua população em dez anos ou de sua área de distribuição em dez anos (Pires-O'Brien 1998), a qual foi estimada no presente trabalho acima de 4 milhões de $\mathrm{km}^{2}$. Ademais, essa espécie é reconhecidamente secundária de vida longa (ter Steege 2000; Selaya 2007) sendo geralmente encontrada, como Couratari oblongifolia (Alvino et al. 2005) em florestas secundárias antigas, o que sugere uma maior resistência em matas alteradas. Esses fatores somados à sua estratégia de regeneração, à diversidade de ambientes onde ocorre e à grande amplitude geográfica indicam C. guianensis coma a espécie de tauari mais generalista (Procópio 2010). No entanto, devido às suas árvores emergentes, com diâmetros relativamente grandes (embora menores que os de C. stellata), esta espécie tem alto valor comercial e deve ser manejada levando em consideração seus baixos valores de abundância. Schulze et al. (2008) mostraram que a exploração de espécies com densidades baixas $(<0,03$ ind./ha, DAP $>50 \mathrm{~cm}$, como foi o caso em duas áreas madeireiras deste estudo) pode levar a um substancial declínio local a médio prazo (30 anos). Além disso, no contexto de fragmentação florestal, o aparecimento de endogamia, associada à incapacidade de seus polinizadores (abelhas euglossines, no caso das Couratari) atravessarem áreas intensamente alteradas, pode aumetar a vulnerabilidade da espécie (Lepsch-Cunha et al. 1999).

Couratari multiflora tem a terceira maior área de distribuição $A$, com numerosas zonas de coleta na região nordeste da Amazônia. Sua distribuição apresenta áreas relativamente grandes com escassez de coletas em regiões cuja flora permanece pouco amostrada (Hopkins 2007). No entanto, a presença da espécie no entorno das bacias dos rios Branco, Madeira e Solimões sugere que ela ocorra nessas regiões. Sua densidade variou em torno de 1 ind./ha, exceto em Sinnamary-GF [IP], onde ela foi a dominante dentre as espécies de tauari (Fig. 4). Em escala local, Lepsch-Cunha et al. (1999) e Collinet (1997) mostraram um padrão agregado de distribuição para C. multiflora, o que Procópio (2010) relacionou a fatores associados à topografia, pois a espécie é menos abundante em baixio. Embora os dados de abundância sejam escassos, é possível observar que a espécie tem um padrão de distribuição amplo, contínuo, porém não uniforme, mais próximo àquele de C. stellata do que ao de C. guianensis.

Enquanto Mori \& Lepsch-Cunha (1995) e LepschCunha et al. (1999) classificaram Couratari multiflora como emergente, neste estudo foram observadas apenas árvores de subdossel ou dossel e com o menor DAP dentre as espécies de tauari, superando apenas os indivíduos de $C$. calycina. A pressão e o impacto da exploração madereira sobre suas populações são reduzidas pela conjunção de um baixo DAP máximo com uma estrutura diamétrica rica nas menores classes (Gayot \& Sist 2004), como observada em Sinnamary-GF [IP]. Ademais, a madeira de C. multiflora apresenta a menor densidade documentada $\left(0,48 \mathrm{~g} / \mathrm{cm}^{3}\right.$, Chave et al. 2006), o que diminui seu interesse madeireiro quando comparada a outras espécies de tauari. Como para C. guianensis, a baixa abundância da espécie em certas áreas deve ser considerada no manejo florestal, tendo em vista o seu importante papel ecológico, pois pertence às poucas espécies que frutificam na estação seca, fornecendo recursos alimentares importantes para a fauna durante este período (Lepsch-Cunha \& Mori 1999).

Cariniana micrantha tem uma área de distribuição ampla e contínua, localizada principalmente nas regiões centro e sudoeste da Amazônia, com provável ocorrência na região dos rios Purus e Juruá, onde a amostragem botânica ainda é pequena (Hopkins 2007). Tanaka (1998) observou alta abundância desta espécie no extremo sul da Amazônia e ter Steege \& Zondervan (2000) a citam entre as árvores mais abundantes no sul da Guiana, porém Huang et al. (2008) relataram a ausência de espécies de Cariniana nessa 
região. Neste estudo, C. micrantha foi mais abundante em Itacoatiara-AM [EM], onde dominou sobre as outras espécies de tauari, e apareceu entre as dez espécies arbóreas mais abundantes na área (Heinrich \& Camino 1997). Nas outras áreas estudadas, as baixas densidades (Tab. 2) sugerem uma repartição pouco uniforme em escala amazônica.

Quanto a densidade da madeira, Cariniana micrantha apresenta a segunda maior do grupo tauari $\left(0,60 \mathrm{~g} / \mathrm{cm}^{3}\right.$, Chave et al. 2006; $0,58 \mathrm{~g} / \mathrm{cm}^{3}$, IBAMA/LPF 2008) e o maior DAP máximo. Esta espécie, bem como C. stellata, pode ser localmente um componente importante do dossel (Hopkins 2005; Mori \& Swarthout 2007), com muitas árvores de $\mathrm{DAP} \geq 80 \mathrm{~cm}$, porém tal característica também a torna de alto valor madeireiro. Seu manejo florestal deve levar em conta não somente a dinâmica da espécie, marcada pelo crescimento lento (Chambers et al. 1998) e a grande longevidade (Laurance et al. 2004; Chambers et al. 1998, embora o dado máximo encontrado - 1400 anos - seja discutido na literatura, Brienen 2005), mas também a variação de sua abundância nas diferentes regiões.

Couratari oblongifolia foi muito coletada na parte leste da Amazônia $\left(d_{\text {próximo }} \approx 100 \mathrm{~km}\right)$, e tem a menor área de ocorrência dentre as espécies de tauari de ampla distribuição (Tab. 3). Depois de C. macrosperma, é a espécie cuja maior proporção da distribuição está situada em regiões com altas taxas de desmatamento (Maranhão, leste do Pará e norte do Tocantins, no arco de desmatamento; Ricardo \& Campanili 2007). Suas árvores alcançam grandes diâmetros, o que aumenta seu valor madeireiro. Na ausência de outros dados, esses aspectos sugerem que esta espécie seja a mais vulnerável dentre as discutidas acima.

Couratari macrosperma não foi encontrada neste trabalho, porém o levantamento nos herbários indicou uma distribuição peculiar. Além da população da Bahia, e duas coletas remotas na Amazônia, todas as coletas de C. macrosperma foram concentradas no sul do bioma (uma zona de coleta a cada $60 \mathrm{~km}$ ). Esta espécie parece rara ou ausente em regiões muito coletadas, próximas à BR-319 e a Manaus. Assim, é possível que sua área real de distribuição seja menor do que sua área $A_{v}$ aqui calculada. Isso implicaria que a principal área de distribuição de $C$. macrosperma esteja reduzida às regiões altamente desmatadas: leste do Acre e Rondônia, região de maior registro também para Allantoma decandra, cuja área de distribuição é a mais ocidental entre as espécies de tauari.

Para as demais espécies de tauari, apesar dos poucos indivíduos encontrados, os dados permitiram apontar a distribuição regional de Couratari tauari e endêmica de C. longipedicellata e C. calycina. Todas elas estão na lista vermelha da IUCN (2010; Tab. 1) por apresentarem áreas de ocorrência menores que $100 \mathrm{~km}^{2}$ (Pires-O'Brien 1998). No entanto, o levantamento nos herbários indicou que a suposta vulnerabilidade de $C$. tauari deve ser revisada, já que depois do registro de novas ocorrências em Paragominas-PA [EM] (Procópio \& Secco 2008) e neste estudo em Belterra-PA [IP], sua área de ocorrência é 1.000 vezes maior do que aquela considerada até então (Tab. 3). Couratari calycina está na lista vermelha por ter registros somente na Guiana (World Conservation Monitoring Centre 1998). No entanto, as várias coletas de herbários e a população inventariada em Sinnamary-GF [IP] apontam a necessidade de revisão das categorias e critérios de ameaça descritos para as espécies de Couratari na lista vermelha da IUCN (2010).

A maioria das espécies estudadas aqui mostrou abundância inferior a 1 ind./ha, confirmando a baixa abundância observada para a maioria das espécies arbóreas da Amazônia (Rankin-de-Merona \& Ackerly 1987; Oliveira 1997; Pitman et al. 2001). Bawa \& Ashton (1991) consideraram espécies com menos de uma árvore adulta por hectare como raras e apontaram a necessidade de se conhecer o tipo de raridade considerando o tamanho e a distribuição das populações, bem como sua auto-ecologia (Leite 2007) para a conservação da variabilidade genética.

Bawa \& Ashton (1991) descreveram quatro tipos de raridade nos trópicos: 1) espécies uniformemente raras ao longo de sua área de distribuição; 2) espécies comuns em certas áreas, mas raras fora delas; 3 ) espécies endêmicas locais; e 4) espécies que ocorrem de forma agregada, mas com abundância populacional baixa. Neste último tipo, quanto maior a abundância no agregado, mais perto do tipo 2 é sua raridade. Couratari longipedicellata e C. calycina, ambas endêmicas e com baixa abundância, pertencem provavelmente ao tipo 3. Couratari tauari, presente em várias áreas deste estudo, mas cuja raridade não permitiu amostrá-la, parece pertencer ao tipo 4. Couratari micrantha, C. stellata, C. multiflora e possivelmente C. oblongifolia mostraram variações de abundância e dominância local que sugerem a classificação delas no tipo 2 . O padrão de distribuição contínuo de $C$. guianensis, porém com abundâncias baixas e bastante homogêneas, se assemelha mais ao tipo 1 . Lepsch-Cunha et al. (1999) classificaram C. multiflora e $C$. guianensis nos tipos 1 e 2 , respectivamente, o que diverge das conclusões deste estudo. Essa discordância ressalta a necessidade de mais inventários locais e regionais para que os padrões de distribuição das espécies amazônicas possam ser apropriadamente caracterizados (Bawa \& Ashton 1991; Hopkins 2007; Schulman et al. 2007).

Várias das espécies de tauari estudadas aqui se distinguem dentre as espécies amazônicas pela ampla distribuição geográfica (e.g. Couratari guianensis), dominância local em abundância e estatura emergente de destaque (Couratari stellata e Cariniana micrantha) ou características fenológicas peculiares (e.g., Couratari multiflora), além de serem frequentes em florestas secundárias antigas (Chambers et al. 1998; ter Steege 2000; Pena-Claros 2001). Essas características, em conjunto, mostram que as espécies de tauari possuem um importante papel na estrutura e no funcionamento da floresta amazônica. Contudo, todas as espécies de tauari de terra firme são exploradas pela madeira ou/e possuem áreas de distribuição suscetíveis à redução. Quando agrupadas como tauari, elas compõem um grupo de alto valor 
comercial devido à sua grande abundância (neste estudo, até 14,4 ind./ha). Neste trabalho, foi observado que o agrupamento mascara a riqueza das áreas, as abundâncias reais, as estruturas diamétricas específicas e a variação do conjunto desses parâmetros entre as áreas. Esses parâmetros podem e devem ser levantados localmente para o manejo adequado das espécies a fim de se estabelecer regras como, por exemplo, a definição de taxas e diâmetros mínimos de corte por espécie. O padrão de distribuição geográfica, determinante para a conservação das espécies, deve ser considerado no manejo e para isso é fundamental se distinguir as espécies.

Tendo em vista o avanço das fronteiras agrícolas e o aquecimento global, a determinação do padrão de distribuição das espécies torna-se fundamental. Se Couratari stellata ocorre realmente em macro-agregados, deve-se assegurar sua permanência onde não for abundante para não isolar suas populações. Por outro lado, espécies generalistas como C. guianensis, apesar da baixa abundância, parecem menos vulneráveis que espécies com subpopulações menores localizadas em áreas mais ameaçadas. Ainda assim, o desequilíbrio geográfico nos inventários e coletas botânicas, conforme demonstrado por Hopkins (2007) e Schulman et al. (2007) e confirmado neste estudo, é particularmente prejudicial na região do arco de desmatamento. Segundo os dados do IBAMA (2007), 70\% da madeira tauari é proveniente dos três principais estados abrangidos pelo arco (Pará, Mato Grosso, Rondônia), onde as espécies são menos conhecidas e a falta de dados impede que sejam realizadas avaliações seguras sobre o grau de ameaça para o grupo tauari.

\section{Agradecimentos}

Ao CNPq, pela bolsa de doutorado cedida a primeira autora; à FAPEAMINPA (Proj. Ecologia e Manejo de Sementes e Mudas) e ao CIRAD (Projeto Floresta em Pé), pelos recursos para coleta de dados. Às instituições de pesquisa: INPA-CPST (em especial ao Dr. Niro Higuchi e sua equipe), Embrapa Amazônia Oriental (Dr. Ademir Ruschel e equipe do Projeto Bom Manejo e ao Dr. Milton Kanashiro e equipe do Projeto Dendrogene), IBAMA, núcleo Santarém e ao CIRAD, núcleo Kurou (Dr. Lilian Blanc e equipe do Projeto ECOFOG); e às empresas madeireiras Precious Woods/Mil Madeireiras, Maflops e Cikel, pelo apóio logístico, pela disponibilização dos dados de inventário e pela atenção dispensada a este trabalho; aos assistentes de campo (mateiros) das seis áreas inventariadas, em especial à memória de Raimundo Feitosa (Raimundinho da Flona); ao Dr. Scott Mori, pela determinação das amostras e atenção imediata diante das dúvidas; aos meus orientadores e aos revisores anônimos, que enriqueceram o conteúdo deste artigo.

\section{Referências}

AIMEX (Associação das Indústrias Exportadoras de madeira do Estado do Pará). 2008. Catálogo florestal. http://www.aimex.com.br/ catalogoflorestal/tauari (Acesso em: 24/09/2008).

Alvino, F.O.; Silva, M.F. \& Rayol, B.P. 2005. Potencial de uso das espécies arbóreas de uma floresta secundária na Zona Bragantina, Pará, Brasil. Acta Amazonica 35(4): 413-420.

Azevedo, C.P. 2006. Dinâmica de florestas submetidas a manejo na Amazônia Oriental: experimentação e simulação. Tese de doutorado, Universidade Federal do Paraná.

Bánki, O.S.; ter Steege, H.; Jansen-Jacobs, M.J. \& Raghoenandan, U.P.D. 2003. Plant diversity of the Nassau Mountains, Suriname. Utrecht, Report of the 2003 Expedition.

Bawa, K.S. \& Ashton, P.S. 1991. Conservation of rare trees in tropical rain forests: a genetic perspective. Pp. 62-74. In: Falk D.A., \& Holsinger
K.E., (eds). Genetics and conservation of rare plants. New York, Oxford University Press.

Brienen, R.J.W. 2005. Tree rings in the tropics: a study on growth and ages of Bolivian rain forest trees. PROMAB Scientific Series 10. PROMAB-Riberalta, Beni.

Brower, J.E.; Zar, J.H. \& Ende, C.N. 1997. Field and laboratory methods for general ecology. 4 ed. Boston, WCB/McGraw-Hill.

Chambers, J.Q.; Higuchi, N. \& Schimel, J.P. 1998. Ancient trees in Amazonia. Nature 39: 135-136.

Chave, J.C.; Muller Landau, H.C.; Baker, T.R.; Easdale, T.A.; ter Steege, H. \& Webb, C.O. 2006. Regional and phylogenetic variation of wood density across 2,456 neotropical tree species. Ecological Applications 16: $2356-2367$.

Collinet, F. 1997. Essai de regroupements des principales especes structurantes d'une foret dense humide apres l'analyse de leur repartition spatiale (Paracou-Guyane). Tese de doutorado, Université Claude Bernard Lyon 1.

Costa, D.H.M.; Carvalho, J.O.P. \& Berg, E. 2007. Crescimento diamétrico de maçaranduba (Manilkara huberi Chavalier) após a colheita da madeira. Amazônia: Ciência \& Desenvolvimento 3(5): 65-76.

Costa, F.R.C. \& Magnusson, W.E. 2003. Effects of selective logging on the diversity and abundance of flowering and fruiting understory plants in a Central Amazonian forest. Biotropica 35(1): 103-114.

Daly, D.C. \& Prance, G.T. 1989. Floristic inventory of the Brazilian Amazon. Pp. 401-426. In: Floristic inventory of tropical countries. New York, New York Botanical Garden.

Duque, A.; Cavalier, J. \& Posada, A. 2003. Strategies of tree occupation at a local scale in terra firme forests in the Colombian Amazon. Biotropica 35(1): 20-27.

Ferreira, S.J.F.; Luizão, F.J.; Miranda, S.A.F.; Silva, M.S.R. \& Vital, A.R.T. 2006. Nutrientes na solução do solo em floresta de terra firme na Amazônia Central submetida à extração seletiva de madeira. Acta Amazonica 36(1): 59-68.

Francez, L.M.B.; Carvalho, J.O.P. \& Jardim, F.C.S. 2007. Mudanças ocorridas na composição florística em decorrência da exploração florestal em uma área de floresta de terra firme na região de Paragominas, PA. Acta Amazonica 37(2): 219-228.

Gayot, M. \& Sist, P. 2004. Vulnerabilité des espèces de maçaranduba face à l'exploitation en Amazonie brésilienne: nouvelles normes d'exploitation à definir. Bois et Forêts des Tropiques 208(2): 75-90.

Gourlet-Fleury, S.; Guehl, J.M. \& Laroussinie, O. (eds.). 2004. Ecology and management of a neotropical rainforest - Lessons drawn from Paracou, a long-term experimental research site in French Guiana. Paris, Elsevier SAS.

Haffer, J. \& Prance, G.T. 2002. Impulsos climáticos da evolução na Amazônia durante o Cenozóico: sobre a Teoria dos Refúgios da diferenciação biótica. Estudos Avançados 16(46): 175-206.

Heinrich, R. \& Camino, R. 1997. Environmentally sound forest harvesting: testing the applicability of the FAO Model Code in the Amazon in Brazil. Forest harvesting case-study 8. Rome, FAO.

Higuchi, N. 2003. Crescimento e incremento de uma floresta de terrafirme manejada experimentalmente e ecofisiologia de suas espécies comerciais. Resumo de Projeto PPD-MCT. http://ftp.mct.gov.br/prog/ ppg7/projetos/30.htm (Acesso em 20/11/ 2008).

Hirai, E.H.; Carvalho, J.O.P. \& Pinheiro, K.A.O. 2007. Comportamento populacional de cupiúba (Goupia glabra Aubl.) em floresta de terrafirme na fazenda Rio Capim, Paragominas (PA). Revista Ciências Agrárias 47: 89-101.

Hopkins, M.J.G. 2005. Flora da Reserva Ducke, Amazonas, Brasil. 2005. Rodriguésia 56(86): 9-25.

Hopkins, M.J.G. 2007. Modelling the known and unknown plant biodiversity of the Amazon basin. Journal of Biogeography 34(8): 1400-1411.

Huang Y.; Mori, S.A \& Prance, G.T. 2008. A phylogeny of Cariniana (Lecythidaceae) based on morphological and anatomical data. Brittonia 60(1): 69-81.

IBAMA (Instituto Brasileiro do Meio Ambiente e dos Recursos Naturais Renováveis). 2006. Documento de origem florestal - DOF, 10 espécies mais comercializadas por estado (tora, madeira serrada), 12/11/2006. http://www.ibama.gov.br/ecossistemas/cgref/publicacoes (Acesso em 10/12/2006). 
IBAMA (Instituto Brasileiro do Meio Ambiente e dos Recursos Naturais Renováveis). 2007. Relatório de qualidade de meio ambiente. Biodiversidade-Flora 12(1). http://www.ibama.gov.br/ojs/index.php/ rqma/issue/view/127/showToc (Acesso em 30/09/2007).

IBAMA/LPF (Instituto Brasileiro do Meio Ambiente e dos Recursos Naturais Renováveis/Laboratório de produtos florestais) 2008. Base de dados de madeiras brasileiras. http://www.ibama.gov.br/lpf/madeira/ caracteristicas (Acesso em 20/09/2008).

IDEFLOR (Instituto de Desenvolvimento Florestal do Pará). 2008 Instrução normativa $\mathbf{N}^{\circ} \mathbf{0 0 3} / \mathbf{2 0 0 8}$ de 20 de fevereiro de 2008. http:// www.ideflor.pa.gov.br/files/u1/IN_003_1.pdf(Acesso 30/09/2008).

ITTO (International Tropical Timber Organization). 2005. Utilization of lesser used wood species in Guyana. Booklet PD 344/05 2(I). 21p.

IUCN (International Union for Conservation Nature). 2010. IUCN Red List of Threatened Species. Version 2010.1. http://ww.iucnredlist.org (Acesso em 28/05/2010).

Laurance, W.F.; Oliveira, A.A; Laurance, S.G.; Condit, R.; Nascimento, H.E.M.; Sanchez-Thorin, A.C.; Lovejoy, T.E.; Andrade, A.; D’Angelo, S.; Ribeiro, J.E. \& Dick, C.W. 2004. Pervasive alteration of tree communities in undisturbed Amazonian forests. Nature 428: 171-175.

Leite, E.J. 2007. State-of-knowledge on Cariniana estrellensis (Raddi) Kuntze (Lecythidaceae) for genetic conservation in Brazil. Research Journal of Botany 2(3): 138-160.

Lepsch-Cunha, N. \& Mori, S.A. 1999. Reproductive phenology and mating potential in low density tree population of Couratari multiflora (Lecythidaceae) in central Amazonia. Journal of Tropical Ecology 15: $97-1212$.

Lepsch-Cunha, N.; Kageyama, P.Y. \& Venconvsky, R. 1999. Genetic diversity of Couratari multiflora and Couratari guianensis (Lecythidaceae): consequencies of two types of rarity in central Amazonia. Biodiversity and Conservation 8: 1205-1218.

Lima, J.R.A; Santos, J. \& Higuchi, N. 2005. Situação das indústrias madeireiras no estado do Amazonas em 2000. Acta Amazonica 35(2): 125-132.

Luizão, F.J. \& Vasconcelos, H.L. A 2005. Floresta tropical úmida (Manaus). http://www.icb.ufmg.br/ peld/site01.html (Acesso em 28/10/2005).

Marín, W.A. \& Flores E.M. 2003. In: J.A. Vozzo (ed.). Tropical tree seed manual - section Species Descriptions. Washington, DC, US Departament of Agriculture, Forest Service. http://www.rngr.net/Publications/ ttsm (Acesso em 20/12/2007).

Martini, A.; Rosa, N.A. \& Uhl, C. 1998. Espécies de árvores potencialmente ameaçadas pela atividade madeireira na Amazônia. Série Amazônia 11. Belém, IMAZON.

Martins-da-Silva, R.C.V.; Hopkins, M.J.G. \& Thompson, I.S. 2003. Identificação botânica na Amazônia: situação atual e perspectivas. Belém, Embrapa Amazônia Oriental. (Documento 169). 81p.

Mori, S.A. \& Boom, B.M. 1987. The forest. In: The Lecythidaceae of a lowland neotropical forest. La Fumée mountain, French Guiana. Memoirs of the New York Botanical Garden 44: 9-29.

Mori, S.A. \& Lepsch-Cunha, N. 1995. The Lecythidaceae of a central amazonian moist forest. Memoirs of the New York Botanical Garden 75: 5-29.

Mori, S.A. \& Prance, G.T. 1990. Flora Neotropica Lecythidaceae- Part II (Couroupita, Corythophora, Bertholletia, Couratari, Eschweilera \& Lecythis), with a study of secondary xylem of Neotropical Lecythidaceae. Flora Neotropica 21(2): 376.

Mori, S.A. \& Prance, G.T. 2006. The Lecythidaceae Pages. New York, The New York Botanical Garden. http://sweetgum.nybg.org/lp/index. html (Acesso em: 20/03/2010).

Mori, S.A. \& Swarthout, D. 2007. Brazil nut family (Lecythidaceae) in the New World. In: C.J. Cleveland (ed.). Encyclopedia of Earth. Washington, D.C., Environment information coalition. National council for science and environment. http://www.eoearth.org/article/ Brazil_nut_family_(Lecythidaceae)_in_the_New_World (Acesso em $15 / 03 / 2010)$.

Oliveira, A.A. 1997. Diversidade, estrutura e dinâmica do componente arbóreo de uma floresta de terra firme de Manaus, Amazonas. Tese de Doutorado, Universidade de São Paulo.
Oliveira, A.N. \& Amaral, I.L. 2004. Florística e fitossociologia de uma floresta de vertente na Amazônia Central, Amazonas, Brasil. Acta Amazonica 34(1): 21-34.

Pélissier, R.; Dray, S. \& Sabatier, D. 2002. Within-plot relationships between tree species occurrences and hydrological soil constraints: an example in French Guiana investigated through canonical correlation analysis. Plant Ecology 162: 143-156.

Pena-Claros, M. 2001. Secondary forest succession: processes affecting the regeneration of Bolivian tree species. PROMAB. Scientific Series 3. Riberalta, PROMAB.

Pires-O’Brien, J. 1998. Couratari guianensis, Couratari longipedicellata, Couratari tauari. In: IUCN 2010. IUCN Red List of Threatened Species. Version 2010.1. www.iucnredlist.org (Acesso em 28/05/2010).

Pires-O'Brien, M.J. \& O’Brien, C.M. 1995. Ecologia e modelamento de florestas tropicais. Pp. 109-143. In: Serviço de informação e documentação. Belém, Faculdade de Ciências Agrárias do Pará.

Pitman, N.C.A; Terborgh, J.W.; Silman, M.R.; Percy Nunez, V.; Neill, D.A.; Ceron, C.E.; Palacios, W.A. \& Aulestia, M. 2001. Dominance and distribuition of tree species in upper Amazonian terra firme forests. Ecology 28(8): 2101-2117.

PNUMA \& OTCA. 2008. Geo Amazônia - Perspectiva do meio ambiente na Amazônia. In: Relatório do Programa das Nações Unidas para o Meio Ambiente e da Organização do Tratado de Cooperação Amazônica. Coord. Universidad Del Pacífico - Centro de investigación. www.pnuma.org (Acesso em: 24/09/2008).

Prance, G.T. 1982. A review of the phytogeographic evidences for Pleistocene climate changes in the neotropics. Annais of Missouri Botanical Garden 69: 594-624.

Prance, G.T. \& Mori, S.A. 1979. Lecythidaceae: The actinomorphicflowered New World (Asteranthos, Gustavia, Grias, Allantoma \& Cariniana). Flora Neotropica 21(1): 271

Procópio, L. C. 2010. Caracterização espacial, estrutural e da dinâmica de populações e auto-ecologia de espécies arbóreas de terra firme da Amazônia, agrupadas sob um mesmo nome vernacular: o exemplo do tauari (Couratari spp.) em uma abordagem para o manejo e conservação. Tese doutorado INPA, Manaus.

Procópio, L.C. \& Secco, R.S. 2008. A importância da identificação botânica nos inventários florestais: o exemplo do "tauari" (Couratari spp. e Cariniana spp. - Lecythidaceae) em duas áreas manejadas no Estado do Pará. Acta Amazonica 38(1): 31-44.

Rankin-de-Merona, J.M. \& Ackerly, D.D. 1987. Estudos populacionais de árvores em florestas fragmentadas e as implicações para conservação in situ das mesmas na floresta tropical da Amazônia Central. IPEF 35: 47-59.

Ricardo, B. \& Campanili, M. 2007. Almanaque Brasil Socio Ambiental 2008. São Paulo, ISA.

Ruokolainen, K.; Tuomisto, H.; Vormisto, J. \& Pitman, N. 2002. Two biases in estimating range sizes of Amazonian plant species. Journal of Tropical Ecology 18: 935-942.

Salomão, R.P.; Vieira, I.C.G.; Suemitsu, C.; Rosa, N.A.S.; Almeida, S.S.; Amaral, D.D. \& Menezes, M.P.M. 2007. As florestas de Belo Monte na grande curva do rio Xingu, Amazônia Oriental. Boletim do Museu Paraense Emílio Goeldi - Ciências Naturais 2(3): 57-153.

Schulman, L.; Toivonen, T. \& Ruokolainan, K. 2007. Analysing botanical collecting effort in Amazonia and correcting for it in species range estimation. Journal of Biogeography 34: 1388-1399.

Schulze, M.; Grogan, J. \& Vidal, E. 2008. Forest certification in Amazonia: standards matter. Oryx 42: 229-239.

Sebbenn, A.M.; Degen, B.; Azevedo, V.C.R.; Silva, M.B.; Lacerda, A.E.B.; Ciampi, A.Y.; Kanashiro, M.; Carneiro, F.S.; Thompson, I. \& Loveless, M.D. 2008. Modelling the long-term impacts of selective logging on genetic diversity and demographic structure of four tropical tree species in the Amazon forest. Forest Ecology and Management 254: 335-349.

Selaya, N.G. 2007. Sprinting, climbing and persisting: light interception and carbon gain in a secondary tropical forest succession. PROMAB Scientific Series 11. Riberalta, PROMAB

Silva, U.S.C. 2003. Fitossociologia do componente arbóreo e não arbóreo de uma floresta tropical em Cantá - RR. Dissertação. Universidade Federal Rural da Amazônia- UFRA, Belém.

Smartwood \& Imaflora. 2005. Resumo público de certificação - Mil Madeireira Ltda (Precious Woods Amazon) - anexo lista de espécies 
exploradas. Estado do Amazonas. http://www.rainforest-alliance.org/ forestry/documents.pdf. (Acesso em 20/03/2008).

Tanaka, A. 1998. Ecofisiologia do estabelecimento de plântulas em plantios de enriquecimento em Novo Aripuanã. Dissertação de Mestrado, Instituto Nacional de Pesquisa da Amazônia, Manaus.

ter Steege, H. 1998. The use of forest inventory data for a National Protected Area Strategy in Guyana. Biodiversity and Conservation 7: $1457-1483$

ter. Steege, H. 2000. Plant diversity in Guyana. With recommendations for a National Protected Area Strategy. Tropenbos Series 18. Wageningen, The Tropenbos Foundation.

ter Steege, H.; Pitman, N.; Sabatier, D.; Castellanos, H; van der Hout, P.; Daly, D.C.; Silveira, M.; Phillips, O.; Vasquez, R., van Ande, T., Duivenvoorden, J., Oliveira, A.A., Renske Ek, R., Lilwah, R., Thomas, R., van Essen, J., Baider, B., Maas, P., Mori, S., Terborgh, J., Nunez Vargas, P., Mogollón, H. \& Morawetz, W. 2003a. A spatial model of tree a-diversity and tree density for the Amazon. Biological Conservation 12: 2255-2277. ter Steege, H.; Laumans, B.; Laumans-Bus, D.; Bongers, F.J.J.M. \& Zondervan, G. 2003b. Long-term effects of timber harvesting in Mapane - North Suriname. Pp. 79-94. In: ter Steege H. (ed.). Longterm changes in tropical tree diversity: studies from the Guiana Shield, Africa, Borneo and Melanesia (Tropenbos series 22). Wageningen, Tropenbos International.

ter Steege, H. \& Zondervan, G. 2000. A preliminary analysis of large-scale forest inventory data of Guiana Shield. Pp. 35-54. In: ter Steege H. (ed.). Plant diversity in Guyana. With recommendations for a National Protected Area Strategy (Tropenbos Series 18). Wageningen, The Tropenbos Foundation.

ter Steege, H.; Nigel, C.A.; Pitman, P.O.L.; Chave, J.; Sabatier, D.; Duque, A.; Molino, J.-F.; Prévost, M.-F.; Spichiger, R.; Castellanos, H.; Hildebrand, P. \& Vásquez, R. 2006. Continental-scale patterns of canopy tree composition and function across Amazonia. Nature 443: 444-447.

World Conservation Monitoring Centre 1998. Couratari calycina. In: IUCN 2010. IUCN Red List of Threatened Species. Version 2010.1. <www. iucnredlist.org >. (Acesso em 26/05/2010). 